\title{
REVIEW
}

\section{Systems for the management of respiratory disease in primary care - an international series: Pakistan}

\author{
*Mohammed Osman Yusuf ${ }^{a}$ \\ a The Allergy and Asthma Institute, Islamabad, Pakistan
}

Received 24th February 2008; accepted 11th March 2008; online 28th June 2008

\begin{abstract}
Introduction: Pakistan has a population exceeding 160 million. Communicable diseases remain the most important health problem in Pakistan, with non-communicable diseases and injuries comprising a quarter of all deaths.

National policy and health service model: The government provides a multi-tiered healthcare system, from the Basic Health Unit at the village level, ranging up to the tertiary care teaching hospitals in the larger cities. These facilities are accessible to all, and are usually free or highly subsidised. Patients have the choice to see a private or government GP, a specialist, or an alternative medicine healer. The current National Health Policy focusses mainly on prevention of communicable diseases, as well as improving primary and secondary health care services.

Epidemiology: Only $6 \%$ of 13 to 14 year olds are medically diagnosed as having asthma, and more than half report symptoms of rhinitis. The prevalence of chronic bronchitis in patients over 65 is $14 \%$ and $6 \%$ in rural females and males, respectively, and $9 \%$ (with no sex difference) in urban areas. The higher rates of chronic bronchitis observed in females in rural areas may be attributed to high levels of indoor air pollution due to cooking over smoking fires. It is estimated that $36 \%$ of adult males, and $9 \%$ of females, smoke, and the cigarette consumption per person per year in Pakistan is among the highest in South Asia. Pakistan is ranked 7th among the 22 highest tuberculosis disease burden countries in the world. In 2006 the number of all TB cases was 76,668 compared to 97,245 in 2004. It is estimated that 70-80,000 people are infected with HIV, but only 3,000 AIDS cases have been reported so far. The incidence of acute respiratory infections in children varies, and is a common cause of morbidity. In adults, it is estimated that pneumonia may affect as many as 2.8 million Pakistanis.

Access to care: Patients usually can access their local GPs or alternative medical practitioners with relative ease. In villages in remote areas, access to government-run health care facilities can sometimes be quite difficult.

Facilities available: Respiratory illnesses like asthma, allergy and COPD, are still a relatively low priority area, and even simple equipment - e.g. a peak flow meter - is not commonly available. Specialised equipment like spirometers and allergy testing facilities are only available in a few larger cities and hospitals.

Future developments: The WHO's Global Alliance against Chronic Respiratory Diseases (GARD) is expected to be launched in 2008. This will be a platform for strengthening primary care respiratory activities with the involvement of the International Primary Care Respiratory Group (IPCRG). Various non-governmental organisations have plans to promote awareness regarding all aspects of allergy, asthma, COPD, and other chronic respiratory diseases, in the future.

(C) 2009 General Practice Airways Group. All rights reserved.

MO Yusuf. Prim Care Resp J 2009; 18(1): 3-9.

doi:10.3132/pcrj.2008.00039
\end{abstract}

Keywords Pakistan, respiratory disease, management, primary care, systems, funding, asthma, infection, COPD, economics, epidemiology, tuberculosis

\section{Contents}

Introduction

Primary care service delivery in Pakistan

Doctors and other health care providers

* Corresponding author: The Allergy and Asthma Institute, No. 275, Gomal Road Sector E-7, Islamabad 44000, Pakistan

Tel: 00-9251-2654465 Fax: 00-9251-2654446 E-mail: osman_allergy@yahoo.com 


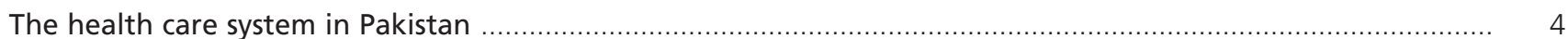

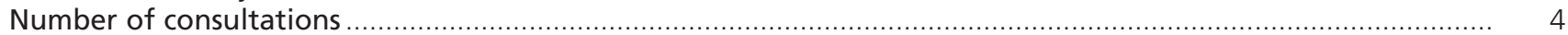

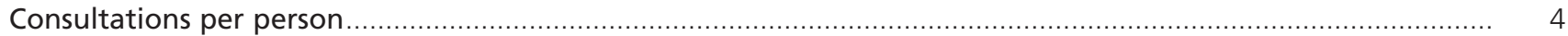

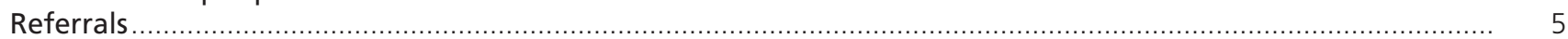

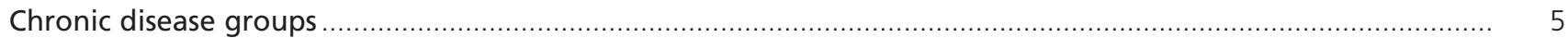

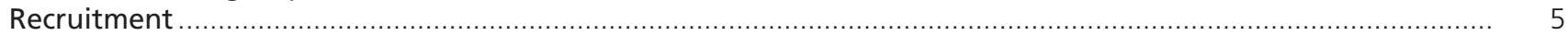

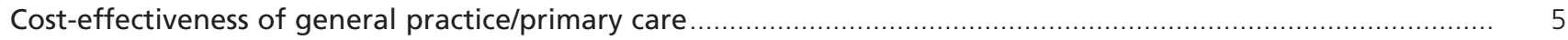

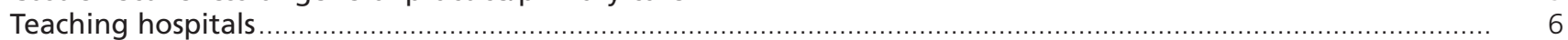

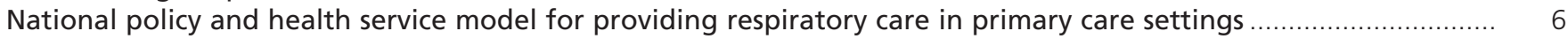

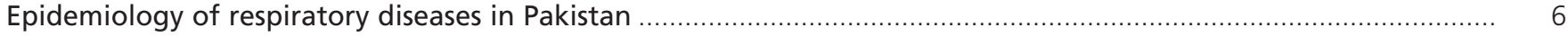

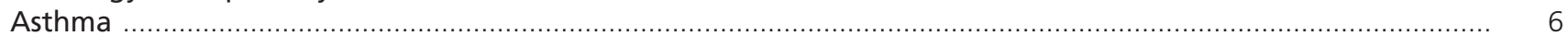

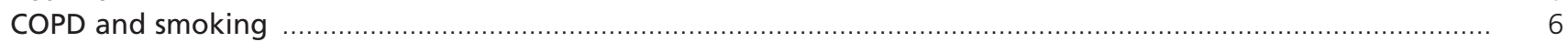

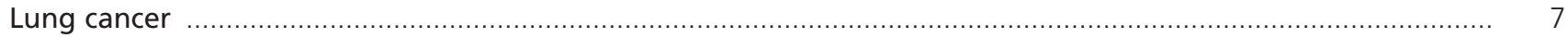

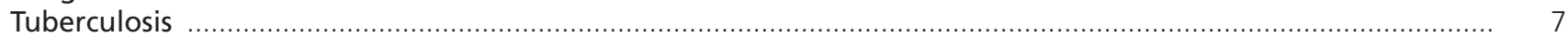

HIV/Aids

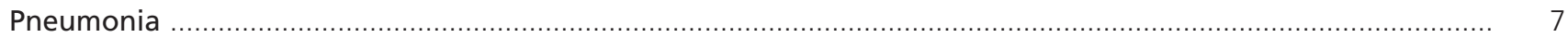

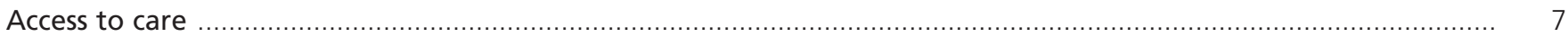

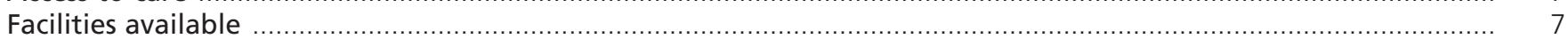

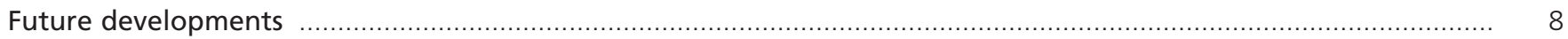

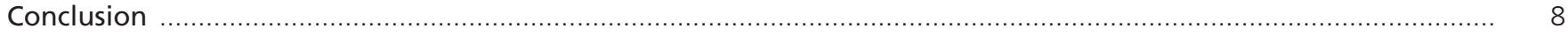

References

\section{Introduction}

This paper on the current provision of primary care services for patients with respiratory disease in Pakistan, is the third in a planned series of international reviews. In keeping with the aims and objectives of the Primary Care Respiratory Journal, the editors commissioned this series of papers to enable clinicians and health service managers to compare and learn from different systems of primary care management for patients with respiratory disease around the world. Each of the papers in the series will follow a similar format, and will include information on national policy and models, epidemiology, access to care, facilities available, and future developments. By summarising and comparing how different countries provide primary care for patients with respiratory disease we hope to stimulate debate and inform the future development of policies aimed at improving the care worldwide for people with respiratory disease.

\section{Primary care service delivery in Pakistan}

Pakistan is the sixth most populous country in the world, with a population exceeding 160 million. Geographically, it covers almost 0.8 million square kilometres ranging from some of the coldest and highest mountainous regions in the world to some of the hottest desert areas. It is divided into four provinces, of which the fertile Punjab is the most densely populated, followed by Sindh, North West Frontier Province (NWFP) and barren Baluchistan.

Between 30 to $35 \%$ of the population is urban, while the remaining rural population live in areas which vary between being well-serviced to those which are totally inaccessible. Forty percent of the population is less than 15 years old, with only $4 \%$ being more than 65 years old. ${ }^{1}$ The average life expectancy for males is 61 years, and for females is 62 years, while healthy life expectancy is 54 and 52 years for males and females, respectively. ${ }^{2}$ The per capita income is US $\$ 2,500$, making Pakistan one of the lower middle income countries of the world, ranked at number 161 by the World Bank based on purchasing power parity (PPP). ${ }^{3}$

\section{Doctors and other health care providers}

There are currently 107,836 registered general practitioners (GPs), and 19,992 specialists of different specialties. ${ }^{4}$ These are supplemented by over 57,000 nurses, 25,000 midwives and 8,500 Lady Health Visitors, and trained paramedical staff, ${ }^{5}$ as well as dedicated community health support workers. ${ }^{6}$

\section{The health care system in Pakistan}

There is a comprehensive, well-developed health care system in Pakistan. This is provided primarily by the government, but is supplemented by private GPs and specialists. This is further augmented by an exhaustive alternative medicine system, which is equally, if not more, popular amongst the masses, and which is more easily accessible and affordable.

\section{Number of consultations}

There are no valid statistics available to gauge the number of consultations per GP per day. However, hospital figures show that an average GP or Medical Officer in an out-patient setting would see around 100 patients per day. An average GP in the private setting would also be seeing the same number of patients, if not many more. Consultation rates of up to 200 patients per day by a single GP are not unusual. The average time that a patient would be spending with a GP is less than 5 minutes.?

\section{Consultations per person}

No national average has been calculated for Pakistan, since 
the consultation for a single malady may not always be confined to a single modality of treatment. Thus, unlike in developed countries, a patient may be consulting alternative medicine practitioners, faith healers, as well as using home remedies for a single ailment, and finally ending up with a qualified GP or specialist if all else fails.

\section{Referrals}

In the primary care setting, there is no organised system of referral by GPs to specialists, since patients are free to choose the specialist of their choice. If a GP does decide to refer to a specialist, the GP will not have any control over whether the patient does, or does not, visit the specialist. In many cases, a patient may visit a specialist directly, as it is not mandatory to be referred by a primary care physician.

A study of 1,150 participants, ${ }^{8}$ aimed at evaluating the pattern of health care utilisation and out-of-pocket expenses incurred in health care, identified that the mean number of contacts was 1.7. Most of the contacts (66.8\%) were with private GPs. The average cost per visit was Pak Rs. 106 (US\$ 1.7) and Rs. 38 (US\$ 0.6) for GPs and public sector providers, respectively. A multiple logistic regression model revealed that those living in urban areas, with monthly household income $>$ Rs 2,500 (US\$ 39.7), an education level > five years, and who received both injections and oral drugs, were more likely to visit private GPs.

In a hospital, however, the GP in the 'filter clinic' or outpatient department will either advise treatment if he or she deems appropriate, or will refer to a specialist without advising any treatment. Therefore the patient is then bound to see the specialist.

\section{Chronic disease groups}

Communicable diseases remain the most important health problem in Pakistan. Lower respiratory infections are the leading cause of mortality causing almost $12 \%$ of all deaths, followed by ischaemic heart disease $(11 \%)$, diarrhoeal diseases $(9 \%)$, perinatal conditions $(8 \%)$, cerebrovascular disease $(6 \%)$, tuberculosis $(5 \%)$, chronic obstructive pulmonary disease $(4 \%)$, measles $(3 \%)$, whooping cough $(2 \%)$, and congenital anomalies $(2 \%)^{8}$

The burden of respiratory diseases is heavy in Pakistan. ${ }^{9}$ This is outlined in Table 1.

Non-communicable diseases and injuries are amongst the top ten causes of mortality and morbidity in Pakistan ${ }^{10}$ and account for almost $25 \%$ of the deaths within the country." One in three adults over the age of 45 years suffers from high blood pressure, and the prevalence of diabetes is reported at $10 \%$. Approximately one million people suffer from severe mental illness and over 10 million individuals from neurotic conditions. ${ }^{3}$

\section{Recruitment}

The government recruits doctors at all levels, ranging from GPs or Medical Officers to specialists, to cater for the increasing demands of the population. It is not mandatory for doctors to specialise; however, they are encouraged to, and are provided with support in case they wish to do so. Annually, local medical schools and international medical graduate certification provides almost 6,800 doctors, 1,150 physicians emigrate, ${ }^{11-13}$ and an estimated 570 physicians stop practising for various reasons. The current ratio for physicians per 1,000 population $(0.473)$ is inadequate to maintain the nation's health. ${ }^{12}$

\section{Cost-effectiveness of general practice/primary care}

Although, like the rest of the world, GP consultations are far cheaper than specialist visits or hospital admissions, there are no formal statistics available to quantify the cost savings or expenditure, due to the wide variety of services provided by the GP and the fee structure in the private setting.

Table 1. The burden of respiratory diseases in Pakistan ${ }^{10}$

\begin{tabular}{|c|c|c|c|c|c|c|}
\hline & Deaths & DALY 2002 & Death rates & DALY Rates & $\begin{array}{c}\text { Age-Std } \\
\text { death rates }\end{array}$ & $\begin{array}{l}\text { Age-Std } \\
\text { DALY rates }\end{array}$ \\
\hline All causes & 1386.4 & 44,821 & 924.8 & 29,899 & 1281.7 & 26,233 \\
\hline Tuberculosis & 67 & 1,288 & 44.7 & 859 & 73.7 & 1,088 \\
\hline HIVIAIDS & 5.1 & 136 & 3.4 & 91 & 4.5 & 112 \\
\hline Respiratory Infections (RTI) & 167.6 & 4,698 & 111.8 & 3,134 & 126.8 & 2,074 \\
\hline Lower RTI & 164.6 & 4,552 & 109.8 & 3,036 & 125.3 & 2,013 \\
\hline Upper RTI & 2.8 & 94 & 1.9 & 63 & 1.4 & 39 \\
\hline Otitis media & 0.2 & 52 & 0.1 & 35 & 0.1 & 22 \\
\hline Respiratory diseases & 62.5 & 1,234 & 41.7 & 823 & 85.8 & 1,007 \\
\hline COPD & 48.6 & 566 & 32.4 & 378 & 71.1 & 584 \\
\hline Asthma & 5.7 & 410 & 3.8 & 273 & 5.5 & 255 \\
\hline
\end{tabular}




\section{Teaching hospitals}

As teaching hospitals are concentrated in the larger cities, and the majority of the population is urban, the need to strengthen rural health services in both the governmental and private sector is paramount.

\section{National policy and health service model for providing respiratory care in primary care settings}

Pakistan is administratively divided into four provinces, which are further divided into divisions, districts, "tehsils" (subdistricts), culminating in the small town or village level. The government attempts to provide healthcare through a threetiered healthcare delivery system and a range of public health interventions. The former includes Basic Health Units (BHUs) and Rural Health Centers (RHCs) which form the core of the primary healthcare structure at the rural level. Secondary care - including first and second referral facilities providing acute, ambulatory and inpatient care - is provided through Tehsil Headquarter Hospitals (THQs), and District Headquarter Hospitals (DHQs) which are supported by tertiary care from teaching hospitals.

Throughout the country, the vast network of health care facilities include 924 hospitals, 5,336 BHUs and Sub-Health Centers, 560 RHCs, 4,712 Dispensaries, 906 MCH Centres and 288 TB Centres. These facilities provide greatly subsidised treatment to all individuals, irrespective of their socioeconomic background. A nominal registration fee is charged, which then entitles the patient to free medical consultations and medication, and usually free, or otherwise grossly subsidised, medical investigations. ${ }^{3}$

The current National Health Policy was devised by the Federal Ministry of Health, Government of Pakistan, in 2001. It has 10 key components focussing mainly on prevention of communicable diseases, (including childhood diseases, TB, malaria, Hepatitis-B and HIV/AIDS) and addressing the inadequacies in primary and secondary health care services. The other components aim at promoting gender equity; bridging nutritional gaps, creating awareness in public health matters, and ensuring availability, affordability and quality of drugs in the country. ${ }^{8}$

Although a key component of the National Health Policy does address the inadequacies in primary and secondary health care services, there is no focus on respiratory care in the primary health sector. Among other factors, it does, however, identify that there is no referral system in operation. ${ }^{13}$

In 2007, the government had allocated a sum of Rs.50 billion (US\$ 0.83 billion or 0.54 billion Euro), which is a mere $0.57 \%$ of GDP. However, this is $25 \%$ more than the previous year. $^{3}$
Despite such a comprehensive and elaborate governmentsponsored healthcare system, patients often have to pay for health services, either because they do not have access to government-provided facilities or because they would prefer to see a private GP or alternative medicine healer. ${ }^{8}$ It is interesting to note that recognised alternative therapies like homeopathy, acupuncture and herbal medicine are also available to the public in government-sponsored institutions and hospitals.

\section{Epidemiology of respiratory diseases in Pakistan}

A study on 13,519 patients conducted in a low socioeconomic setting in Karachi, Pakistan's largest city, revealed that respiratory diseases were the most predominant, affecting $26.5 \%$ of all the patients. ${ }^{14}$

\section{Asthma}

The International Study on Asthma and Allergies in Childhood (the ISAAC Study) constitutes the only reliable data available on the prevalence of allergic rhinitis and asthma in Pakistan. The study interviewed 3,231 randomly-selected school children between the ages of 13-14 years old within Islamabad city; it revealed that $16.3 \%$ had a history of wheezing, but only $6 \%$ of them were medically diagnosed as having asthma. Boys (18\%) outnumbered the girls (13.6\%) in this age group. More than half of the children reported symptoms of rhinitis. ${ }^{15}$

\section{COPD and smoking}

The National Health Survey of Pakistan (NHSP) 1990-94 estimated that the prevalence of chronic bronchitis increased over the age of 65 years, being 14\% among rural females and $6 \%$ among rural males. In the urban areas, prevalence was $9 \%$ among both males and females. It has been hypothesised that higher rates of chronic bronchitis observed in females in the rural areas is attributable to high levels of biomass fuel exposure due to cooking over smoking fires. ${ }^{16,17}$

The World Health Organisation estimates that $36 \%$ of adult Pakistani males, and $9 \%$ of females, smoke. ' According to the United Nations Development Programme report of August 2002, cigarette consumption per person per year in Pakistan was the highest in South Asia, with Rs 560 million going up in smoke daily. In Pakistan, the estimated COPD mortality rate is 71 deaths per 100,000, the fourth highest rate among the 25 most populous nations in the world. It was also revealed that 1,200 children in the 6-16 years age group took up smoking every day in Pakistan. ${ }^{16}$

The NHSP showed that huqqa (water pipe) and chewing tobacco was commonest among men and women aged 65 years and above. According to this survey, smoking was commoner in rural compared with urban areas $^{18}$ and higher among the illiterate $(41.2 \%) .^{19}$ 


\section{Lung cancer}

The incidence of lung cancer is also showing an increase in both the older (65+) and the younger (35-49) age groups, which corresponds to the trends in smoking prevalence. ${ }^{20}$

\section{Tuberculosis}

Pakistan is ranked 7th among the 22 highest disease burden countries in the world. The estimated annual incidence of all types of TB cases is 177/100,000 population. The WHO's recommended Directly Observed Treatment Short Course (DOTS) protocol has being implemented since 2000. By the year 2006 the absolute number of all TB cases was 76,668 as compared to 97,245 in the year 2004. The percentage case detection rate is $50 \%$, treatment success rate is $84 \%$, while cure rate is $71 \%$. The TB Control Program was revived in the year 2000. A medium-term (2006-2010) TB Control Program has been approved at a cost of Pak Rs. 1.18 billion. ${ }^{21}$

\section{HIV/AIDS}

According to UNAIDS estimates, some $70-80,000$ persons, or 0.1 percent of the adult population in Pakistan, are infected with HIV, although cases reported to the National AIDS Control Programme are less..$^{22}$ The National AIDS Programme's latest figures show that around 3,000 AIDS cases have so far been reported since 1986. The Government of Pakistan launched an active and comprehensive National AIDS Prevention and Control Programme in 1987.23

\section{Pneumonia}

Acute Respiratory Infections (ARI) in children have been well documented in Pakistan. Incidence of ARIs in children varies in different communities and is a common cause of morbidity. ${ }^{24}$ However, in adults, the figures are not so reliable. According to one estimate, pneumonia may affect as many as 2.8 million Pakistanis. ${ }^{25}$

\section{Access to care}

Patients are free to access health care facilities of their choice. This is usually guided by accessibility, affordability, but most of all, peer pressure. A large number of Pakistanis do not believe in the allopathic (conventional) system of medicine, and prefer traditional therapies, leaving the "medical" system as a last resort.

The community or family GP, or the Medical Officer (GP equivalent) in the hospital out-patients department, is usually the first line healthcare professional to see most patients. ${ }^{26}$ In most cases, this visit is sufficient for treatment of the patient, leaving a very small number who seek referral, or who prefer to visit a specialist.

Respiratory illnesses, excluding tuberculosis and chest infections, are not included in the priority areas of the health care system in Pakistan, with the result that asthma, respiratory allergies and COPD, are often under-diagnosed and inappropriately treated. Studies on tuberculosis, diabetes and asthma conducted in Pakistan on general practitioners' knowledge and skill to diagnose and manage such diseases conclude that they do not have the required acumen. ${ }^{25,27-29}$

In the primary care setting the GP usually does not have a preference for adult or paediatric patients, and neither is he "disease- or organ-specific". Hence, excluding a handful of GPs, most would be seeing children, adults and even geriatric cases, with all types of acute and chronic illnesses. At a specialist level, the demarcation between paediatricians and adult physicians is very clear. However, there is no further differentiation into "Paediatric Pulmonologists" or "Adult Asthmologists" etc. in most cases. A paediatrician will see all types of child patients, including pulmonary, while a pulmonologist will see all types of chest patients.

Specialised nursing is also still in its infancy in Pakistan, with the majority of specialist nurses being trained in accident and emergency, cardiology, public health, and community nursing etc. There are just a handful of "asthma nurses" in Pakistan. Health educators for respiratory illnesses are mainly focussed on TB, and are usually found in dedicated TB and Chest hospitals in the country.

At secondary and tertiary care level, the care becomes more organ- and disease-specific, with separation into adult and paediatric hospitals and care facilities.

If the millennium development goals highlighted in the 1978 Alma Ata Conference are to be achieved by 2015, revitalisation and effective implementation of primary health care will be a vital reform..$^{28}$ It has been recommended that decentralisation of services will mature into institutionalisation of health services at the district level, and this will help in strengthening primary health care services. ${ }^{29}$ A two-year Health Sector Reforms Programme (HSRP) initiated in Pakistan's largest province, Punjab, has shown a rise in the recruitment of healthcare providers in remote rural facilities..$^{30}$

\section{Facilities available}

In the recent past, the trend of primary care physicians to "specialise" or focus on one particular disease or organ system, is increasing. This is mostly seen for diabetes, hypertension, and other chronic diseases. Accordingly, the GP will equip himself/herself with the relevant equipment, laboratory and facilities. However, as respiratory illnesses like asthma, allergy and COPD, are still a relatively low priority area, even simple equipment like peak flow meters are not common, let alone spirometers and allergy testing equipment etc. This is the same in the private and in the government sector. Diagnostics for TB and chest infections are more common and easily accessible.

Secondary and tertiary care institutions do have the relevant equipment, but not many patients have access to such facilities. 
Allergy testing and specific immunotherapy are not easily available in Pakistan. One government institution is providing non-specific allergy testing (doing tests for "pollen" and "dust"), and non-specific therapy, which is in total contradiction to the international and WHO guidelines on this form of treatment. The results, if any, are very poor, and have given a bad reputation to this form of therapy in Pakistan. This treatment is available in the private sector, but is expensive, and out of reach of the common man.

\section{Future developments}

The future of primary care services, especially those for respiratory illnesses in Pakistan, is very bright.

It is planned to launch the Global Alliance against Chronic Respiratory Diseases (GARD), a WHO Global initiative, in Pakistan in 2008. Initial negotiations are already underway, and the GARD country initiator for Pakistan has chalked up a comprehensive multi-tiered plan in this regard. ${ }^{31}$ The World Health Organisation has a keen interest in promoting health services in Pakistan, since its very inception. ${ }^{32}$

Further improvement is envisaged with a more formalised and stronger relationship with the IPCRG to follow from 2008, following the launch of the GARD. Already, GPs have shown their keen interest in the IPCRG-Pakistan, and more than 1,000 have already joined this group. It is expected that members of the Academy, College and Society of General Practitioners, Pakistan, will also join this group.

Another key factor promoting awareness, training and public health education programmes on respiratory illnesses (including allergy and asthma at all levels of society ranging from schoolchildren to health care professionals) is the forthcoming collaboration between the Allergy and Asthma Institute of Pakistan and the Global European Allergy and Asthma Network (GA2LEN), which is under negotiation. ${ }^{33}$

The Aga Khan Hospital, Karachi, a key institution in promoting health care at the primary, secondary and tertiary level in Pakistan, is also enhancing its collaboration with other organisations in Pakistan for the dissemination of knowledge regarding asthma, COPD, and other CRDs. ${ }^{34}$

Recently, there has been a focus on non-communicable diseases (NCDs), in the community brought about by a very successful partnership between the Ministry of Health, the World Health Organisation in Pakistan, and a private organisation, Heartfile. This organisation has identified the need for more focus on chronic respiratory diseases. ${ }^{11}$

\section{Conclusion}

As the prevalence of chronic respiratory disease continues to increase globally, Pakistan is no exception. Given the high disease prevalence, it is imperative that appropriate strategies must be devised to deal with these issues more effectively.
Provision of high quality health care has always been a priority of the government, but this has been limited by the lack of qualified and trained medical and public health personnel, financial limitations, and other logistic support. Fortunately, the focus is now changing, and health care is receiving a slightly larger share of the GDP budget.

The shortfall of specialised personnel is also being gradually overcome, and it will not be long before primary care will see a significantly favourable change in the early management of chronic respiratory disease. The Primary Care Physician will continue to be the backbone of support for the healthcare system, and it is imperative that he/she must be strengthened in terms of facilities, education, and back-up support, to be able to provide the best possible health care to one of the largest nations in the world.

\section{References}

1. World Health Organisation. Official website. Available at http://www. emro.who.int/emrinfo/index.asp?Ctry=pak (accessed on 13 January, 2008).

2. WHOSIS, WHO Statistical Information System, 2007. Available at: http://www.who.int/countries/pak/en/. (accessed 30 January, 2008)

3. World Development Indicators database, World Bank, 14 September 2007 Available at http://siteresources.worldbank.org/DATASTATISTICS/Resources/ GNIPC.pdf (accessed on 30 January, 2008).

4. Pakistan Medical and Dental Council. Available at http://www.pmdc org.pk/stat.htm (accessed on 13 Jan, 2008)

5. The Economic Survey, Ministry of Finance, Government of Pakistan 2006-7. pp 175-188. Available at http://www.finance.gov.pk/survey/sur_chap_06-07/12Health.PDF. (Accessed 13 Jan 2008).

6. Smith S, Kelly A, Randhawa G. The provision of primary care interventions by community health support workers in Pakistan. Community Pract 2007; 80(4):18-22

7. Training Programme in Allergy and Asthma for Primary Care Physicians Bhurban, Pakistan 2003. Personal Communication.

8. World Health Organisation Statistics. Death and DALY estimates by cause, 2002 http://www.who.int/entity/healthinfo/statistics/bodgbddeathdalyestimates.xls (accessed on 13th January, 2008)

9. Global Burden of Disease Estimates. World Health Organisation 2007. Available at http://www.who.int/healthinfo/statistics/bodgbddeathdalyestimates.xls (accessed 30 January, 2008).

10. Hyder AA, Morrow RH. Lost healthy life years in Pakistan in 1990. Am J Public Health 2000;90:1235-40. doi:10.2105/AJPH.90.8.1235

11. Pakistan Demographic Survey 2001. Federal Bureau of Statistics, Statistics Division, Government of Pakistan, Islamabad, Pakistan: Government of Pakistan, 2003.

12. Talati JJ, Pappas G. Migration, medical education, and health care: a view from Pakistan. Acad Med 2006;81(12 Suppl):S55-62. doi:10.1097/01. ACM.0000243543.99794.07

13. The National Health Policy 2001. Ministry of Health, Government of Pakistan.December 2001. Available at http://siteresources. worldbank.org/PAKISTANEXTN/Resources/Pakistan-DevelopmentForum/NationalHealthPolicy.pdf . (accessed 13 January, 2008).

14. Anjum Q, Alam E, Rizvi R, Usman J, Shaikh S, Ahmed Y. Morbidity pattern and utilization of a primary health care center in a low socioeconomic area of Karachi. J Pak Med Assoc 2006;56(1):13-16.

15. Yusuf MO, Yusuf SO, Khan MS, Mahmood N. Rhinitis and Asthma in 13-14 year old school Children in Islamabad, Pakistan. American College of Allergy, 
Asthma \& Immunology Annual Meeting, November 4 to 9, 2005, Anaheim, California, USA. Abs 950516

16. Nishtar S. National Action Plan for Prevention and Control of NonCommunicable Diseases and Health Promotion in Pakistan. A joint publication of the Ministry of Health, Government of Pakistan; the World Health Organization, Pakistan office, and Heartfile. Available at http://www.heartfile.org/ (accessed January 13, 2008).

17. Akhtar T, Ullah Z, Khan MH, Nazli R. Chronic bronchitis in women using solid biomass fuel in rural Peshawar, Pakistan. Chest 2007;132(5):1472-5 doi:10.1378/chest.06-2529

18. Pakistan Medical Research Council. National Health Survey of Pakistan 199094. Islamabad, Pakistan. Pakistan Medical Research Council, Network Publication Service, 1998.

19. Pakistan Medical Research Council. Pakistan Health Education Survey (ISBN: 969-499-003-3 [pbk]). Islamabad, Pakistan: Pakistan Medical Research Council, 2003.

20. Bhurgri $Y$, Bhurgri A, Usman A, et al. Patho-epidemiology of lung cancer in Karachi (1995-2002). Asian Pac J Cancer Prev 2006;7(1):60-4

21. WHO REPORT 2007 Global Tuberculosis Control. Available at http://www.who.int/GlobalAtlas/predefinedReports/TB/PDF_Files/pak.pdf (accessed 14 January, 2008).

22. UNAIDS Website. Available at http://www.youandaids.org/Asia\%20Pacific\% 20at\%20a\%20Glance/Pakistan/index.asp\#scenario (accessed 13 January, 2008)

23. National AIDS Control Programme, Government of Pakistan. Press Release on World AIDS Day, 1st Dec. 2007

24. Nizami SQ, Bhutta ZA, Hasan R. Incidence of acute respiratory infections in children 2 months to 5 years of age in periurban communities in Karachi, Pakistan. J Pak Med Assoc 2006;56(4):163-7

25. Country Statistics for Pneumonia. Avaiable at http://www.cureresearch.com/ p/pneumonia/stats-country.htm. (accessed 14 January, 2008).

26. Marsh D, Hashim R, Hassany $F$, et al. Front-line management of pulmonary tuberculosis: an analysis of tuberculosis and treatment practices in urban Sindh, Pakistan. Tuber Lung Dis 1996;77:86-92. doi:10.1016/S0962-8479(96)90082-

27. Shehzadi R, Irfan M, Zohra T, Khan JA, Hussain SF. Knowledge regarding management of tuberculosis among general practitioners in northern areas of Pakistan. J Pak Med Assoc 2005;55(4):174-6.

28. Shaikh BT, Kadir MM, Pappas G. Thirty years of Alma Ata pledges: is devolution in Pakistan an opportunity for rekindling primary health care? J Pak Med Assoc 2007;57(5):259-61.

29. Shaikh BT, Rabbani F. The district health system: a challenge that remains. East Mediterr Health J 2004;10(1-2):208-14

30. Javed TA, Amin S. Health sector reforms programme in Punjab: a primary healthcare initiative. Clin Med 2007;7(1):19-22.

31. Bousquet J. Chairman, WHO-GARD. Personal Communication. December 2007

32. Gezairy HA. The grave problems being faced by our health sector. J Pak Med Assoc 2004;54(8):430-3.

33. Yusuf SO. Medical Director, The Allergy \& Asthma Institute, Pakistan. Personal Communication. December 2007.

34. Khan JA. Professor of Medicine, Aga Khan University Hospital, Karachi. Personal Communication. 2007.

\section{Available online at http://www.thepcrj.org}

